\title{
CULTURAS QUE TAMBÉM SE EXPRESSAM EM PORTUGUÊS: FORMAÇÃO DE LEITORES POR MEIO DE POEMAS AFRICANOS NA EJA
}

CULTURES THAT ALSO EXPRESS THEMSELVES IN PORTUGUESE: TRAINING OF READERS THROUGH AFRICAN POEMS AT EJA

Fábio Roberto Ferreira Barreto' Emerson da Cruz Inácio²

1 Mestrando pelo programa de Estudos Comparados de Literaturas de Língua Portuguesa da USP, é docente da rede municipal de São Paulo, e-mail: fabrobferbar@gmail.com.

2 Livre-Docente pela USP, titular no Departamento de Estudos Comparados de Literaturas de Língua Portuguesa da mesma instituição, e-mail: einacio@usp.br. 
RESUMO: Trata-se de experiência atinente à formação de leitores por meio de poemas de literatura africana, que se desenvolveu no projeto, de cunho interdisciplinar e étnicoracial, Culturas Que Também Se Expressam Em Português com turmas de EJA (Educação de Jovens e Adultos) da escola pública EMEF CEU Cantos do Amanhecer, da DRE-CL (Diretoria de Ensino de Campo Limpo), da Secretaria Municipal de Educação de São Paulo, em 2016.

PALAVRAS-CHAVE: Leitura literária; Educação; Interdisciplinaridade; Literatura Africana de Língua Portuguesa; étnico-racial.

ABSTRACT: This is an experience related to the formation of readers through poems of African literature, which was developed in the project, of an interdisciplinary and ethnoracial nature, Cultures that are also showed in Portuguese with classes of EJA (Youth and Adult Education) from the public school EMEF CEU Cantos do Amanhecer, from DRE-CL (Board of Education of Campo Limpo), from the Municipal Education Secretary of São Paulo, in 2016.

KEYWORDS: literary reading - education - interdisciplinarity - African Portuguesespeaking literature - ethnic-racial 


\section{INTRODUÇÃO}

Apresentada no XVIII Seminário de Estudos Comparados de Literaturas de Língua Portuguesa, na Primavera de 2018, a comunicação Sobre Culturas Que Também Se Expressam Em Português motivou a publicação deste artigo. Decorrem, pois, tais iniciativas - comunicação oral (naquele ano) e, por conseguinte, produção escrita (neste) - da opção de seu autor: enfatizar a importância das práticas de leitura literária no lócus escolar pelo viés da apreciação estética. Em vez de ampliar a discussão acerca de textos sobre crítica literária, o que também é demasiadamente necessário, aposta-se, aqui, na urgência pedagógica de como engendrar didáticas direcionadas ao gosto pela leitura; neste caso específico, em consonância com o programa ao qual é vinculado como mestrando. Ao compartilhá-la, crê o autor contribuir para discussão acerca das responsabilidades - e possibilidades - que o docente de Língua Portuguesa tem na formação do gosto pela leitura.

No entendimento do autor do texto, a Faculdade de Filosofia, Letras e Ciências Humanas da Universidade de São Paulo precisa ampliar a discussão acerca de metodologias de ensino de leitura literária em programas de graduação e pós-graduação oferecidos pela Faculdade de Letras. Em seu retorno à instituição, após mais de uma década, o mestrando identifica algumas tentativas na faculdade que visam à aproximação entre teoria literária e didáticas de ensino. A despeito de serem louváveis, tais ações se devem mais à militância de alguns docentes do que ao cumprimento de conteúdo programático estabelecido pelos pares como condição sine qua non para formação - senão ideal ao menos mais condizente - com o que se espera de um bacharel em Letras na sociedade. Trata-se, na concepção deste mestrando, de tarefa que essa unidade tem no dever de cumprir, em parceria com a Faculdade de Educação; por meio da qual a USP oferece os cursos de licenciatura. Em outras palavras, além de know how para fazer crítica literária, o egresso de um curso de Letras precisa ter também saberes para formar leitores.

Peculiarmente, a experiência pedagógica sobre a qual se debruça o pesquisador é multifacetada, tanto nas particularidades dos objetos literários quanto nas especificidades do grupo discente a que se dirigiu. Em razão do ensino de literaturas africanas 
de língua portuguesa não constituir uma prática frequente na EJA (Educação de Jovens e Adultos), a EMEF (Escola Municipal de Ensino Fundamental) CEU (Centro Educacional Unificado) Cantos do Amanhecer, no primeiro semestre de 2016, desenvolveu o projeto Culturas Que Também Se Expressam Em Português. Seu principal objetivo foi formar o gosto pela leitura por meio de poemas africanos de língua portuguesa, embasando sua ação em fundamentos da crítica literária e, especialmente, do ensino de leitura literária ao grupo estudantil que compõe tal modalidade de ensino. Atrelaram-se a tal trabalho, obviamente, muitos outros propósitos - tais como conhecer aspectos da geografia e da história africanas -, os quais são tão nobres quanto este para o desenvolvimento de aulas em prol de educandos desse segmento.

Ao introduzir essa prática pedagógica, a equipe teve a sensibilidade de pautar outro aspecto particular: garantir que a discussão sobre um tema de eixo étnico-racial fosse desenvolvida sem que tivesse de atrelá-la especificamente a datas que fizessem referência à temática (tais como a de 21 de março ${ }^{3}$, Consciência $\mathrm{Negra}^{4}$, etc.). Considerando as exigências legais e os percentuais de estudantes negros e pardos matriculados em EJA na sua unidade escolar, a equipe resolveu iniciar o ano letivo com um projeto que tratasse esse assunto a partir de textos literários, por meio do qual, interdisciplinarmente, as demais áreas de conhecimento pudessem engendrar ações para oportunizar acesso a um repertório cultural que, historicamente, é negado a estudantes brasileiros e, por conseguinte, discutir estereótipos sobre a África.

\section{A ESCOLA (PÚBLICA) NÃO É UMA BOLHA BRANCA}

Observar a diversidade étnica e, por conseguinte, cultural é condição indispensável para o êxito do fazer pedagógico. Em se tratando do contexto no qual está inserida a unidade escolar, algumas considerações se fazem necessárias. Há uma diversidade étnica brasileira e, por conseguinte, na escola pública paulistana que

3 Dia Internacional de Luta pela Eliminação da Discriminação Racial.

4 Dia Nacional da Consciência Negra. 
merecem alguns apontamentos. As questões étnico-raciais, não raro, suscitam paradoxos. Segundo dados mais recentes do $\mathrm{IBGE}^{5}, 54,9 \%$ da população brasileira são compostos por negros e pardos; isto é, a maioria absoluta, ante os $44,2 \%$ que se declaram brancos. Todavia, outros números apresentados pelo mesmo IBGE inserem a população negra em um quadro de segregação a minorias: em 2017, o rendimento médio dos brancos era de $\mathrm{R} \$ 2.814,00$, contra $\mathrm{R} \$ 1.606,00$ de pardos e $\mathrm{R} \$ 1.570,00 \mathrm{de}$ pretos; ainda em 2017, a taxa de desocupação era 9,5\% entre brancos contra $14,5 \%$ entre pardos e 13,6\% entre pretos; de acordo com dados de 2016, o analfabetismo era de $4,2 \%$ na parcela branca da sociedade e de $9,9 \%$ no segmento pardos e pretos, mais do que o dobro. Isto é, existe uma matemática perversa na qual a quantidade de negros e pardos maior no país, contraditoriamente, se converte em qualidade de vida menor para esse mesmo grupo nesta terra.

Na cidade de São Paulo, em um comparativo com os dados do IBGE, os indicativos demonstram uma proporção distinta em números quantitativos, mas não deixa de corroborar a exclusão qualitativa que a análise sobre a situação geral que o país apresenta. Conforme publicação de orientação pedagógica da SME-SP (Secretaria Municipal de Educação de São Paulo), de “10.886.000 pessoas (que residiam no município), 67\% eram brancas e 30\%, negras (e pardas)”6 ${ }^{\prime}$ O número de educandos negros e pardos matriculados nas modalidades de ensino infantil, fundamental e médio da rede municipal representava "mais de 50\% (SÃO PAULO, 2008, 11)" do total de 936.000 estudantes estimados pela SME-SP. Impressionantemente, cerca de 230 mil estudantes desse total não souberam definir sua cor, o que provavelmente implicaria em elevação de percentuais referentes a negros e pardos em escolas públicas da maior rede municipal de ensino do país. Embora não haja indicativos sobre a modalidade de EJA (Educação de Jovens e Adultos) na capital paulista, sua realidade, provavel-

5 Divulgados em 24.11.2017, apresenta resultados de Pesquisa Nacional por Amostragem de Domicílios Contínua 2016. Disponível em: < https://agenciadenoticias.ibge.gov.br/agencia-noticias/2012-agencia-de-noticias/noticias/18282-populacao-chega-a-205-5-milhoes-com-menos-brancos-e-mais-pardos-e-pretos>. Acesso em 27 de março de 2019.

6 De acordo com IBGE, em 2007, consoante documento do município de São Paulo. 
mente, não difira das outras etapas de escolarização na rede municipal. Assim como no restante do Brasil, os problemas socioeconômicos afetam de modo mais incisivo o segmento da população negra e parda desta cidade.

\section{EMEF CEU Cantos do Amanhecer}

A EMEF CEU Cantos do Amanhecer é uma das setenta e sete unidades de ensino dessa esfera na Diretoria de Ensino de Campo Limpo (DRE-CL). Desse universo, atualmente, quarenta unidades oferecem a modalidade de ensino EJA Regular ${ }^{7}$, números semelhantes aos de 2016, ano letivo em que se desenvolveu o projeto.

É preciso registrar que no primeiro semestre de 2016, a EMEF CEU Cantos do Amanhecer constituía-se como a maior unidade educacional da DRE-CL, com mil e setecentos estudantes matriculados em todas as modalidades de ensino, de regular, anos iniciais e finais do fundamental, e de EJA. Nesse período, nessa última modalidade eram exatamente cento e vinte e oito educandos, distribuídos em quatro turmas: uma de quarta etapa final (equivalente a nono ano regular), duas de quarta etapa inicial (equivalente a oitavo ano regular) e uma de terceira etapa final (equivalente a sétimo ano regular).

A despeito de este autor não dispor de uma pesquisa com metodologia científica, tem-se a sondagem de que a maioria dos educandos de EJA do primeiro semestre de 2016 identificava-se como negro ou pardo. Alguns registros fotográficos atestam que um número expressivo de negros e pardos compunha o corpo discente dessa modalidade de ensino. Se houvesse outros tipos de registro, ter-se-ia a comprovação por meio de dados quantitativos atinentes ao que se assumiam como negros no início e, também, foram se assumindo negros no decorrer do trabalho, demonstrando a importância de tal projeto para questões identitárias; a lacuna provocada pela ausência de tabulação de dados, entretanto, não implica em falta de instrumentos para aferir de outros modos a eficácia do projeto.

7 A rede municipal de ensino oferece cinco formas de "atendimento da Educação de Jovens e Adultos na Cidade de São Paulo", das quais EJA Regular é a mais comum (com aulas ministradas exclusivamente à noite). Na Diretoria Regional de Ensino, há (em 2019), além das quarenta unidades mencionadas no texto, um CIEJA (Centro Integrado de Educação de Jovens e Adultos). 


\section{INTERVENÇÃO PEDAGÓGICA}

\section{À QUESTÃo IMPOSTA, UMA POSSIVEL RESPOSTA}

Ao deparar com a composição do grupo estudantil de EJA da EMEF CEU Cantos do Amanhecer, em 2016, o grupo de professores e de gestão escolar, que já desenvolvera projetos relevantes sobre questões étnico-raciais, em distintas modalidades de ensino, entendeu ser urgente elaborar uma estratégia específica para atender à demanda local.

Uma vez que também para a equipe escolar "trabalhar com projetos constitui-se uma prática pedagógica significativa, porque [...] promove uma aprendizagem baseada na problematização e na investigação da realidade" (SÃO PAULO, 2016, p. 28), a discussão, naquele momento, se converteu sobre como engendrar uma ação que ocorresse para a "realização de projetos de diferentes naturezas, no decorrer do ano letivo" (BRASIL, 2010, p. 22). Isto é, não bastava propor uma ação em um momento letivo específico, mas alternar estratégias no decorrer do ano.

Essa discussão foi fundamental para que o projeto se iniciasse no começo do primeiro semestre, não no início do segundo semestre, tampouco apenas no último bimestre, quando o mês de novembro suscita algumas intervenções, as quais, ainda que pertinentes, não têm o mesmo alcance que pode ter um projeto que se proponha desde o começo do ano letivo. Foi consenso para toda a equipe que o

educador, de posse do conhecimento de sua área de atuação, politicamente comprometido com os contextos e territórios onde atua e cujo planejamento é gestado coletivamente e alinhado ao PPP da unidade educacional e do espaço educativo, terá no diálogo a efetivação de uma EJA: princípios e práticas pedagógicas, metodologia de trabalho que respeita as especificidades educacionais, sociais e culturais dos educandos (SÃO PAULO, 2016, p. 27-28)

Optou-se, após se discutir sobre outras interessantes possibilidades, pelo projeto Culturas Que Também Se Expressam Em Português. A sugestão trazida pelo autor deste texto, como docente da área de língua portuguesa da unidade escolar, visava à implementação de estudos de literaturas africanas produzidas em português, por meio de quais 
se privilegiasse a fruição literária e, por conseguinte, a ampliação do repertório cultural sobre a África, especialmente no que concerne à discussão acerca de estereótipos sobre o continente, impedindo, a partir de suas premissas, que tal prática apenas fosse "não só de denúncia da miséria e discriminações que atingem o continente" (BRASIL, 2010, p. 21). Ademais, articular um projeto que tenha a leitura literária como eixo central na EMEF CEU Cantos do Amanhecer é ser coerente com o território no qual está inserida, uma vez que saraus e $\operatorname{slams}^{8}$ atuam fortemente na região, inclusive, nas escolas públicas.

Dentre os objetivos específicos, listam-se alguns relevantes:

desenvolver senso crítico sobre questões relacionadas ao colonialismo do Século XIX, sobretudo permitindo compreender melhor as razões pelas quais a desigualdade social é mais acentuada na África do que, em geral, em outros continentes; problematizar estereótipos sobre o continente africano, tais como: crer que a África é um país, não um continente; acreditar que apenas existem savanas e tribos não urbanas; supor que todo africano é igual, ignorando etnias, línguas, culturas, traços físicos; supor que culturas provenientes de etnias africanas são inferiores, em especial às de matrizes europeias; estimular a curiosidade sobre contribuições africanas para o mundo, em particular o Brasil. (Excerto do projeto Culturas que também se expressam em português - grifos nossos)

Assim, em consonância com documentos oficiais, Culturas Que Também Se Expressam Em Português pretendeu ser, ainda, "uma resposta, entre outras, na área da educação, à demanda da população afrodescendente (...) bem como direito dos negros de se reconhecerem na cultura nacional"9 (grifos nossos) (BRASIL, 2004 p. 10).

A utilização de textos literários, propositando o prazer, serviu de mote para que os demais professores pudessem inserir em seus planejamentos estratégias variadas para amplificar a temática. A direção adotada pelo educador era a de que sob

8 Também conhecido como Poetry Slams, é conhecido como batalhas de poesia. Surgiu nos EUA, nos anos de 1980, o Slam foi implementado por Roberta Estrela D'Alva em 2008 por meio do trabalho ZAP (Zona Autônoma da Palavra).

9 Diretrizes Curriculares Nacionais para a Educação das Relações Etnicorraciais e para o Ensino de História e Cultura Afro-Brasileira e Africana: página 10, 2004. 
sua regência prevaleceria a preocupação com a fruição de textos. Acordou-se - entre os pares - que entre uma e duas aulas semanais de cada disciplina, ao menos, seriam dedicadas ao desenvolvimento do projeto.

\section{A AÇÃO EM SEU DESENVOLVIMENTO}

Semanalmente, o professor de Língua Portuguesa apresentava, de forma breve, o poeta a ter poemas inseridos no projeto. Na sequência, em parceria com o POIE (Professor Orientador de Informática Educativa) ${ }^{10}$, projetavam-se dois ou três textos poéticos em um telão. Assim, propiciava-se a oportunidade para que os estudantes acompanhassem visualmente os versos à medida que eram declamados, facilitando o andar da aula no que concerne à seus objetivos. Geralmente, as discussões se estendiam para outras aulas da disciplina de Língua Portuguesa.

Em algumas oportunidades, o combinado era para que a fruição se desse pela declamação em vídeo, de modo que se pudesse oferecer aos educandos outras performances, que não a de educadores e de outros estudantes; memorável inclusive, foi a recepção que os estudantes fizeram à Súplica, de Noémia de Sousa ${ }^{11}$, tanto na interpretação do artista multifacetado Marcelino Freire quanto na interpretação do rapper Emicida. Os estudantes, ainda sobre o texto da poetisa moçambicana, comentaram por muitos dias como Súplica tem a ver com o Brasil periférico que eles habitam, pois, ainda que haja precariedade social, os finais de semana são regados à musica de diferentes estilos (sertanejo, samba, funk), fazendo jus à ideia de que sem as melodias musicais a vida seria impossível: “Tirem-nos tudo/ Mas deixem-nos a música”, lembraram eles por muito tempo dos versos do poema. Não raro, como último registro sobre essa etapa, reuniam-se duas turmas para que se aproveitasse de modo mais eficaz os recursos de Sala de Informática.

Após a fruição, procurava-se incitar os educandos a se expressarem sobre os

10 Nomenclatura alterada em 2020: Professor Orientador de Educação Digital.

11 Uma das expoentes da literatura africana, Noémia de Sousa é conhecida como mãe dos poetas moçambicanos. 
poemas. Explanou-se, desde o primeiro momento, que ninguém deveria se sentir obrigado a explicar uma composição poética em sua totalidade, uma vez que, como todo texto, especialmente literário, existe mais de uma possibilidade de construção de sentidos. Procurou-se, diuturnamente, demonstrar aos estudantes que na educação atualmente existe o entendimento de que "diferentes interpretações [...] provocam diferentes associações e emoções" (BRASIL, 2001, p. 77), tornando interessantes os confrontos entre distintas opiniões sobre os mesmos textos.

Ademais, tratou-se de estimular o estabelecimento de paralelos entre os textos do projeto e outros textos e contextos. Por incentivar a leitura sem imputar obrigatoriedade de avaliações, considerável número de estudantes participou mais ativamente, outros menos; no entanto, segundo depoimentos recolhidos do corpo discente, ao final do semestre, todos afirmaram ter gostado do projeto. Além disso, percebeu-se maior desinibição de todos, maior autonomia na apreensão de ideias e na competência de atribuir sentidos ao texto literário, bem como maior vontade de interagir com composições poéticas.

No corredor, um painel destinado a divulgar poemas abordados no projeto era constantemente renovado. Nele eram afixados os poemas utilizados nas aulas, bem como algumas informações sobre os poetas. Por meio de tal estratégia, vislumbrou-se oportunizar a fruição desses textos a todos os outros estudantes da escola, bem como a pessoas da comunidade que transitam por ali - especialmente, responsáveis por educandos e perueiros.

Os meios digitais também foram utilizados para promover a circulação de textos. Os estudantes de EJA de cada turma tinham um grupo de Whatsapp por meio do qual o professor de Língua Portuguesa compartilhava textos e vídeos. Fazia parte da estratégia idealizada pelo educador usar aparelhos de celular para difundir poemas de autores africanos por meio de contatos de Whatsapp e páginas do Facebook dos estudantes. A recepção à propositura docente foi bastante positiva, no geral: alguns deles compartilhavam entusiasticamente, nos depoimentos em sala de aulas, como tinha sido boa a receptividade de amigos e familiares; outros de modo menos alegre, apesar de declarar que postavam textos, não tinham retorno. Um grupo bem reduzido, por não utilizar ou não demonstrar interesse em tal prática, não experimentou 
compartilhar poemas. Em se tratando de circulação de textos literários, é louvável considerar que não fosse pela intervenção da escola um grupo significativo de pessoas (entre estudantes e demais envolvidos) teriam continuado a ignorar - e por conseguinte - não exercer seu direito a fruir Literatura Africana de Língua Portuguesa.

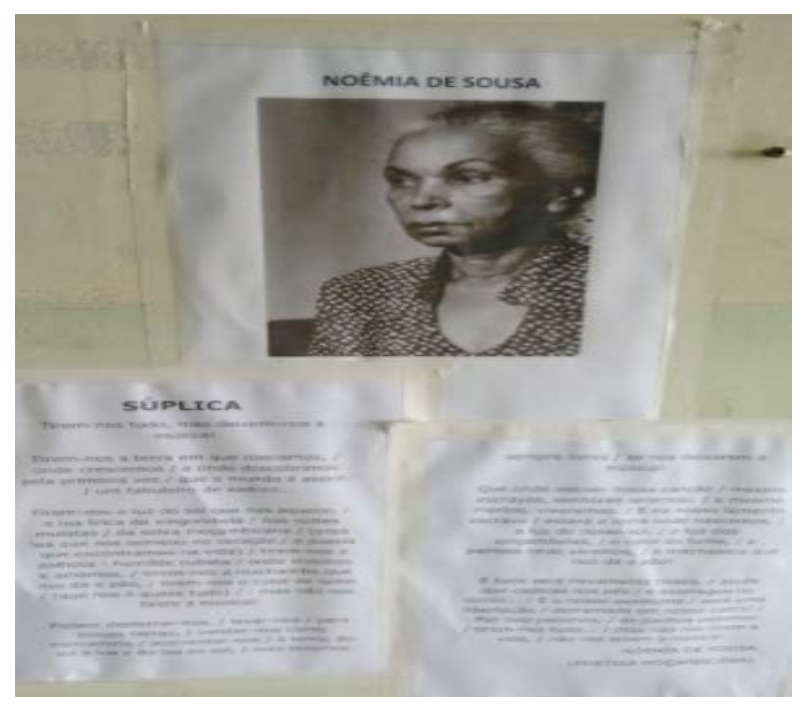

Figura 1: Painel do Projeto, foto de Noémia de Sousa, poema Suplica e informações sobre a poetisa Fonte: Arquivo do autor

Ressalta-se que alguns poemas, sempre com informações sucintas sobre o projeto, foram afixados em pontos de ônibus e em outra escola do bairro (EE Professor Francisco de Paula Conceição Júnior, na qual lecionava o responsável pelo projeto). Vale registrar que os estudantes envolvidos no projeto visitaram o Sarau da Cooperifa, conhecido pelo epíteto de Quilombo Cultural ${ }^{12}$, vivenciando, pela primeira vez, a experiência da palavra literária viva, para realizar, posteriormente, um sarau na escola em que estudavam. Também receberam visitas de representantes da cultura periférica engajados em questões que fazem parte da pauta do movimento negro, tais como a de Sérgio Vaz, ainda no primeiro semestre, e a de Chapinha do Samba da Vela ${ }^{13}$, no transcorrer do segundo semestre.

12 Quilombo Cultural é uma expressão cunhada pelo poeta Sérgio Vaz, fazendo reminiscência ao valor de resistência que a palavra "quilombo" tem na história brasileira, acrescentando o adjetivo atinente à "cultura" para expressar ao processo de lutar por meio da cultura por um país melhor.

13 Sua visita só foi possível no segundo semestre. 


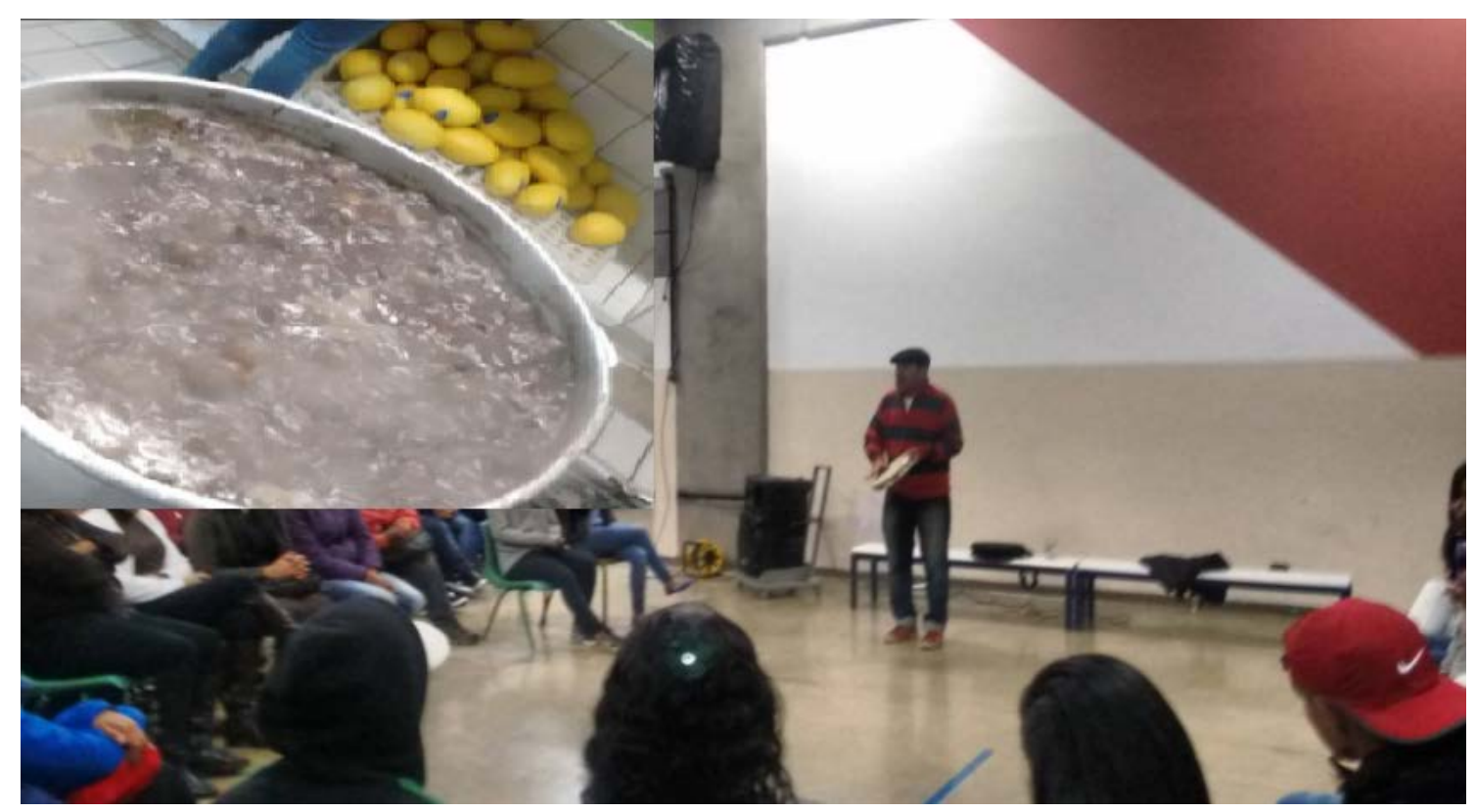

Foto 1: Chapinha, do Samba da Vela, com estudantes da EJA CEU Cantos Fonte: Arquivo do autor

Aferiu-se, no transcorrer do projeto, que as descobertas sobre um continente cuja história tem muito a ver com o Brasil despertaram diferentes sentimentos nos estudantes: desde o encantamento por conhecer aspectos da África e de suas peculiaridades, acerca de quais muitos não possuíam nem sequer noção, até o de indignação por terem passado parte de suas trajetórias escolares sem que nenhuma oportunidade, até então, lhes fossem dadas para que pudessem se inteirar dos conhecimentos que sustentaram o projeto.

\section{A IMPORTÂNCIA DA LITERATURA}

Mais do que discutir sobre literatura, é preciso promover o direito ao fruir estético nas salas de aulas.

\section{ENSINO DE LEITURA LITERÁRIA}

Apesar de se constituir como um dos direitos inalienáveis do ser humano, o acesso à arte não é universalizado no Brasil. Em se tratando de literatura - quer pelo 
preço do livro, quer pela necessidade de tempo para ler -, imputa-se uma gama de dificuldades a mais para o direito à imaginação, que as artes podem propiciar.

Para tornar mais problemática a reflexão, a escola, muitas vezes a única instituição que permite o acesso à leitura, nem sempre cumpre bem seu papel. Muitos estudantes de EJA assumiram que nunca leram nem sequer um livro na escola ou fora dela. Apesar de parte de eles dizer que já tinha realizado a leitura integral de um livro de literatura em âmbito escolar, número razoável afirmou inicialmente não gostar de fazer leituras literárias. Em todos os casos, geralmente, a leitura se associava à obrigação e à realização de tarefas escolares. É o que Michèle Petit aponta quando destaca que "o efeito da escola sobre o gosto pela leitura é muitas vezes complexo" (PETIT, 2008, p. 154); que, tanto pode ampliar o gosto pela leitura como pode inibi-lo, pendendo com certa frequência para essa última opção.

Desde a primeira ação do projeto, envidaram-se esforços para que se ampliasse o gosto daqueles que já possuíam prazer pela leitura, bem como se provocasse naqueles que não o detinham ainda. Em outras palavras, a preocupação central era a de garantir experiências com objetos estéticos de forma a garantir que nem se constituísse mero entretenimento, tampouco fossem meros pretextos a intermediar outros conhecimentos. Apesar de inserido em projeto interdisciplinar, não perdera o foco central de sua ação: literatura como fonte de fruição estética, especialmente, e, também, como de conhecimento.

Para se atingir um público tão heterogêneo (adolescentes, idosos, pessoas de meia idade, alguns que estavam há décadas fora da escola e outros que nem saíram dela, apenas mudaram de modalidade de ensino), a meta foi diversificar. Afinal, se "não se trata de aprisionar o leitor, mas, sim, de lhe apresentar pontes e permitir que ele mesmo construa as suas" (PETIT, 2008, p. 184), foi preciso dimensionar o modo de atingir e envolver o corpo discente para que tamanho trabalho não resultasse em nenhum ou quase nenhum cumprimento de metas.

Reconhecendo sentidos nos poemas do projeto, almejava-se que os estudantes pudessem projetar outras leituras sobre textos e vidas. Por essa razão, ao se selecionar os textos poéticos, houve o cuidado para que mesclassem temáticas e estilos, de modo a permitir a apreciação ampla de obras da Literatura Africana produzida em 
Língua Portuguesa. Previu-se de antemão que alguns poemas teriam a possibilidade de causar impacto maior sobre um grupo específico de estudantes, bem como certas composições poéticas teriam efeitos maiores sobre outros, mas que, no geral, a impressão que todos tivessem da antologia proposta fosse aquela que as literaturas africanas de língua portuguesa pudessem oferecer: de qualidade.

\section{Descobrindo Literaturas Africanas em Português}

É imprescindível, em contexto escolar, garantir o acesso a objetos estéticos que não fazem parte do cotidiano dos estudantes nem das mídias que eles acessam com mais facilidade (jornais impressos, programas televisivos ou de rádios). Por isso, o projeto teve a intenção de partir da literatura para promover o conhecimento de aspectos da cultura e de história africanas de países que utilizam o idioma português como oficial. Senão a escola, em um país no qual o gozo a obras literárias não é direito de todos, que outra instituição poderia possibilitar o acesso à literatura produzida em solo africano? (Quiçá saraus e slams!)

A Lei 10.639/03 imputa a obrigatoriedade do ensino de História e Cultura Afro-Brasileira em todos os estabelecimentos educacionais do país. A despeito da exigência legal e do engajamento de militantes, ainda se faz necessário promover discussões sobre como implementar a lei sem repetir estereótipos ou apenas cumprir de forma superficial tal legislação. Assim, Culturas Que Também Se Expressam Em Português atendeu não só a prescrições oficiais, mas também ao dever moral de reformular o currículo da rede municipal de ensino.

Em se tratando de literatura, ao se oportunizar o acesso a poemas produzidos em língua portuguesa por povos africanos possibilitou-se atingir distintos objetivos: garantir a fruição literária; permitir acesso a objetos estéticos de Literatura Africana de Língua Portuguesa; oferecer textos motivadores, a partir dos quais a discussão sobre aspectos de cultura africana.

Uma vez que se pretendeu contar uma nova narrativa dos povos africanos, iniciou-se o projeto por meio de Karingana ua karingana, de José Craverinha. 


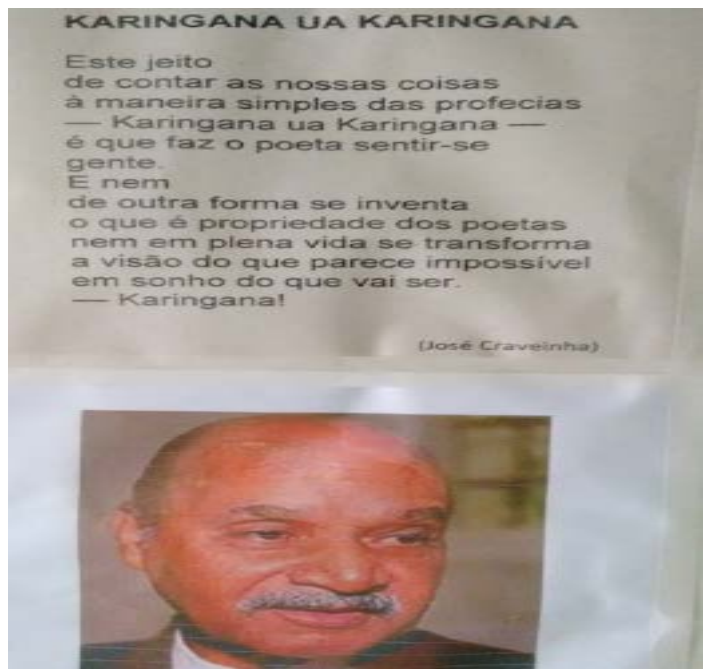

Figura 2: Painel do Projeto, foto de José Craverinha, poema Karingana ua karingana Fonte: Arquivo do autor

Após abrir o projeto com Karingana ua karingana, outros poemas foram inseridos. Foram aproximadamente trinta textos poéticos utilizados, sendo sempre duas ou três composições poéticas de cada um: a) Angola - António Jacinto; Agostinho Neto; Jofre Rocha; b) Cabo Verde - Corsino Fortes; Eugênio Tavares; c) Guiné-Bissau - Almícar Cabral; d) Moçambique - José Craverinha; Noémia de Souza; e) São Tomé e Príncipe - Caetano de Costa Alegre; Alda Espírito Santo.

Propositando ampliar a competência docente para conduzir o projeto, procurou-se subsidiar o olhar do professorado de Língua Portuguesa que esteve à frente do projeto com críticas literárias produzidas por quem vem se debruçando sobre as literaturas africanas de língua portuguesa há um bom tempo. Leituras de textos concebidos por teóricas como a professora Rita Chaves (USP) embasaram a ação pedagógica. Na introdução de $O$ passado presente na literatura africana, a docente universitária faz uma observação que foi de extrema relevância para o projeto:

Profundamente marcada pela História, a literatura dos países africanos de língua portuguesa traz a dimensão do passado como uma de suas matrizes de significado. A brusca ruptura no desenvolvimento cultural do continente africano, o contato com o mundo ocidental estabelecido sob a atmosfera de choque, a intervenção 
direta na organização de seus povos constituíram elementos de peso na reorganização das sociedades que fizeram a independência de cada um de seus países. Tão recentes, e feitas no complexo quadro da conjuntura internacional dos anos 70, essas independências não dariam conta do desejo de acertar o passo na direção do projeto utópico que mobilizara os africanos. Como herança, o colonialismo deixava uma sucessão de lacunas na história dessas terras e muitos escritores, falando de diferentes lugares e sob diferentes perspectivas, parecem assumir o papel de preencher com o seu saber esse vazio que a consciência vinha desvelando (CHAVES, 2004, p. 147).

Por se tratar de poetas que, apesar do traço de africanidade em comum, têm características particulares, procurou-se trazer informações biográficas e ressaltar-se as peculiaridades de cada um deles. Esse procedimento objetivou respeitar as escritas poéticas de cada um dos literatos escolhidos para fazer um pequeno recorte da Literatura Africana de Língua Portuguesa. Aliás, durante todo o projeto, explicitou-se que, mesmo sendo representativos, os poetas apresentados constituíam apenas pequena parte da grande produção literária africana de língua portuguesa; outrossim, que tal recorte estava circunscrito a um gênero particular, dentre tantos outros - o romance, o conto, a crônica, o teatro -, produzidos nesse idioma. E, por sua vez, que há literaturas em outras línguas no continente mãe, com características peculiares, que, como as do idioma utilizado neste projeto, também têm sua grandeza.

\section{CONSIDERAÇÕES FINAIS}

A repercussão do projeto foi bastante positiva. Eixo motriz da ação docente, o ensino de leitura literária permitiu experiências que os educandos revelaram nunca ter vivenciado em lócus escolar. Realizar leituras sem a exigência de fazer uma devolutiva por meio de provas ou atividades de interpretação, especialmente por meio de escrita, foi algo novo e prazeroso. Some-se a isso a descoberta de uma outra África, distante do imaginário que povoava suas mentes, sobretudo por causa da mídia. Ve- 
rificar o sentimento de pertencimento impactante entre os estudante foi, sem dúvida, uma das maiores marcas de Culturas Que Também Se Expressam Em Português.

Sabe-se que a questão da identidade é bastante flexível. "A identidade cultural não é fixa, é sempre híbrida" (HALL, 2003, p. 432-433). Em se tratando de um grupo social privado de acesso a saberes e vivências de ordem variada, sob a perversa influência das mídias, especialmente a TV, as discussões promovidas a partir da implementação do projeto, efetivamente, possibilitaram reflexões sobre identidade étnica e cultural que os estudantes, segundo seus depoimentos, nunca tinham realizado. $\mathrm{O}$ posicionamento de cada um, no que concerne à assunção de sua identidade negra - ou de sua condição de membro de uma sociedade mestiça que frequentemente se orgulha de sua matriz europeia, mas ignora sua ascendência africana - foi se realizando aos poucos, conforme o andamento dos trabalhos.

É mister ressaltar, ainda, que a realização do projeto Culturas Que Também Se Expressam Em Português dialoga com Documento Base Nacional, para EJA. Consoante ao item 15 desse importante documento legal, o projeto desenvolvido na EMEF CEU Cantos do Amanhecer "encara a diversidade como substantiva na constituição histórico-social-cultural e étnico-racial brasileira" (BRASIL, 2008, 2). A equipe docente da escola compreende que, conforme o item 34, o "currículo para EJA não pode ser previamente definido" (BRASIL, 2008, 4); por isso, ao implantar um projeto que elege a leitura literária de textos de autores africanos, em português, possibilitou não apenas cumprir seu ofício pedagógico, mas contribuiu, efetivamente, para promover o respeito à "diversidade" (BRASIL, 2008, 1) e o combate à "desigualdade" (BRASIL, 2008, 1).

Encerrando, é preciso registrar que ter a oportunidade de trazer à discussão a experiência pedagógica Culturas Que Também Se Expressam Em Português no XVIII Seminário de Estudos Comparados de Literaturas de Língua Portuguesa e na Revista Literartes me animam bastante. Essas - bem como outras - iniciativas do Programa propiciam discussões sobre metodologias e didáticas atinentes ao ensino de leitura literária; aulas, eventos e revistas ligados ao Programa, efetivamente, são louváveis na Faculdade de Filosofia, Letras e Ciências Humanas. Sinalizam, inclusive, que as mudanças estão em processo nessa importante faculdade da Universidade de São Paulo. Entretanto, parece haver um longo caminho a percorrer para que, em termos 
bem comuns, a teoria literária e prática docente ocupem o currículo e, consequentemente, a formação de futuros profissionais da educação para o ensino de leitura (literária, especialmente) na educação básica. 


\section{REFERÊNCIAS}

BRASIL. Educação para jovens e adultos: ensino fundamental: proposta curricular primeiro segmento. São Paulo: Ação Educativa/Brasília: MEC, 2001. Disponível em: http:portal.mec.gov.br/secad/arquivos/pdf/eja/propostacurricular/ primeirosegme/proposta curricu lar.pdf. Acesso em 12 de mar. 2019.

BRASIL. Diretrizes Curriculares Nacionais para a Educação das Relações Etnicorraciais e para o Ensino de História e Cultura Afro-Brasileira e Africana. Brasília: MEC, 2004. Disponível em:<http://www.educadores.diaadia.pr.gov.br/arquivos/File/formacao_acao/dcn_relaoes_etnico_raciais.pdf>. Acesso em $20 \mathrm{de}$ dezembro de 2020.

BRASIL. Orientações e ações para a educação das relações etnicorraciais. Brasília: SECAD, 2010. Disponível em: http://etnicoracial.mec.gov.br/images/pdf/publicacoes /orientacoes acoes_miolo.pdf. Acesso em 12 de mar. de 2019.

BRASIL. Proposta curricular para a educação de jovens e adultos segundo do ensino fundamental. Vol. 2. Brasília: SECAD, 2010.. Disponível em: http://portal.mec. gov.br/secad/ arquivos /pdf/vol2_linguaportuguesa.pdf. Acesso em 27 de mar. de 2019.

CHAVES, Rita. O passado presente na literatura africana. Revista Atlântica, São Paulo, n.7, 147-161, 2004. Disponível em: http://www.revistas. usp.br/ viaatlantica/article/view/49794/53898. Acesso em 17 de mar. de 2019. HALL, Stuart. Da diáspora: identidades e mediações culturais. Organização Liv Sovik. Belo Horizonte: Editora UFMG, 2003.

IBGE. Pesquisa Nacional por Amostragem de Domicílios Contínua 2016. Disponível em: < https://agenciadenoticias.ibge.gov.br/agencia-noticias/2012-agencia-de-noticias/noticias/18282-populacao-chega-a-205-5-milhoes-com-menos-brancos-e-mais-pardos-e-pretos >. Acesso em 27 de março de 2019.

PETIT, Michèle. Os jovens e a leitura: uma nova perspectiva. Trad. Celina Olga de Souza. São Paulo: Editora 34, 2008. SÃO PAULO. Secretaria Municipal de Educação. Educação de Jovens e Adultos: princípios e práticas. (V.1) São Paulo: SME/ DOT, 2016. 
SÃO PAULO. Secretaria Municipal de Educação. Educação de Jovens e Adultos: princípios e práticas - volume 2. São Paulo: SME / DOT, 2016.

SÃO PAULO. Secretaria Municipal de Educação. Orientações Curriculares: expectativas de aprendizagem para a educação etnicorracial na educação infantl, ensino fundamental e médio. São Paulo: SME/ DOT, 2008. 